\title{
Evaluating the Efficacy of Lotion Containing Black Rice Bran (Oryza sativa L. indica) Extract as Skin Brightening Agent: A Clinical Trial
}

\author{
Mahdi Jufri ${ }^{1,}{ }^{*}$, Afifah Vardhani ${ }^{1}$ and Erni Purwaningsih ${ }^{2}$ \\ ${ }^{1}$ Faculty of Pharmacy, Universitas Indonesia, Indonesia \\ ${ }^{2}$ Department of Pharmacy, Faculty of Medicine, Universitas Indonesia, Indonesia \\ "Corresponding author: Faculty of Pharmacy, Universitas Indonesia, 16424, Indonesia. Email: mahdi.jufri@farmasi.ui.ac.id \\ Received 2021 May 03; Revised 2021 June 20; Accepted 2021 June 22.
}

\begin{abstract}
Background: Ultraviolet exposure is an extrinsic factor to initiate melanogenesis, the process of melanin formation in the skin. Nowadays, natural ingredients tend to be more prevalent in cosmetic formulations due to consumers' concern about synthetic ingredients and the risks they may represent for human health. Rice bran, the outer layer of a rice grain, can be utilized as a skinlightening agent.

Objectives: This study aimed to determine the efficacy of a lotion containing black rice bran (Oryza sativa L. indica) ethanolic extract as a skin lightening agent.

Methods: The black rice bran ethanolic extract was formulated into oil in water (o/w) lotion. In this study, 34 women applied the lotion at one side of the forearm and base placebo lotion as control at the other side of forearm. The results were tested with a paired $t$-test by GraphPad Prism 8.3.0 software.

Results: There was a significant decrease in the melanin index and erythema index in the forearm with a lotion containing black rice bran extract (P-value $<0.0001$ ).

Conclusions: The lotion containing 10\% black rice bran extract was effective as a skin lightener because it effectively reduced skin melanin production when applied topically.
\end{abstract}

Keywords: Black Rice Bran, Skin Lightening Agent, Natural Product, Clinical Trials, Oryza sativa L. indica

\section{Background}

Ultraviolet irradiation, through several pathways, could modulate melanogenesis, which is the process of melanin formation in the skin. It is a complex process involving the activities of tyrosinase and other tyrosinaserelated proteins (1-3). Tyrosinase inhibition is one of the most common mechanisms used to achieve skin lightening (4). The search for non-cytotoxic natural whitening is based on the fact that natural ingredients tend to be more prevalent nowadays in cosmetic formulations due to consumers' concern about synthetic ingredients and the risks they may represent for human health (5). Natural products and their derivate are known to be a potential source as biologically active ingredients used in phyto-cosmetics (6).

Rice bran, an abundant rice mill by-product containing gamma oryzanol, could be used as a skin brightening agent (3). Miyazawa et al. (7) reported that $0.4 \mathrm{mg} / \mathrm{ml}$ black rice bran extract inhibited tyrosinase activity by $80.5 \%$. The dry black rice bran (Oryza sativa L. indica) contained 118.572 $\mathrm{mg} / \mathrm{g}$ of gamma oryzanol, and the extract inhibited tyrosinase activity at an IC50 of $74.8 \mu \mathrm{g} / \mathrm{mL}$ (8). Gamma oryzanol in bran is a ferulic acid belonging to the phenolic compound $(9,10)$. Ferulic acid is the dominant phenolic acid in bran, containing $56-77 \%$ of the total phenol $(11,12)$.

Tyrosinase is an enzyme that plays a role in the formation of melanin in the epidermis. Its mechanism of action is catalyzing L-tyrosine's hydroxylation reaction to L-DOPA and the oxidation of L-DOPA to dopaquinone, the two main reactions in melanin biosynthesis. Dopaquinone is a compound with a very high reactivity that can polymerize to form a dopachrome, which then forms melanin (13).

\section{Objectives}

The present study aimed to evaluate the effects of lotion containing $10 \%$ black rice bran extract on skin 
melanin and erythema index. The effects produced by this lotion were compared with placebo, which is a base lotion without black rice bran (Oryza sativa L. indica) extract.

\section{Methods}

\subsection{Materials}

\subsubsection{Plant Material}

Black rice bran was obtained from Ciletuh Geopark in Sukabumi, West Java, and authenticated (No.1672/II.CO2.2/PL/2020) at School of Life Science and Technology, Institut Teknologi Bandung, Indonesia.

\subsubsection{Chemicals}

In this study, we used ethanol 96\% (Merck, Germany), demineralized aqua (Brataco, Indonesia), olive oil (Brataco, Indonesia), vaseline album (Brataco, Indonesia), dimethicone (Brataco, Indonesia), cetyl alcohol (Brataco, Indonesia), isopropyl myristate (Brataco, Indonesia), span 80 (Brataco, Indonesia), propylparaben (Brataco, Indonesia), BHT (butylated hydroxytoluene) (Brataco, Indonesia), tween 80 (Brataco, Indonesia), methylparaben (Brataco, Indonesia), and glycerin (Brataco, Indonesia).

\subsection{Method}

\subsubsection{Preparation of Plant Extract}

The black rice bran was extracted using maceration for three days using $96 \%$ ethanol in a 1:4 (w/v) ratio. The mixture was evaporated in a water bath at $80^{\circ} \mathrm{C}$ for $24 \mathrm{~h}$ to obtain a slimy mixture after the maceration process.

\subsubsection{Preparation of Lotion}

The oil-phase materials consist of olive oil, vaseline album, dimethicone, cetyl alcohol, isopropyl myristate, span 80 , and melted at $70^{\circ} \mathrm{C}$. Furthermore, BHT was melted into the oil phase. Materials in the water phase consisted of propylparaben, tween 80 , methylparaben, and glycerin. They were dissolved in demineralized aqua at $70^{\circ} \mathrm{C}$.

We mixed the oil phase and the water phase at $70^{\circ} \mathrm{C}$ and used a homogenizer for 15 minutes at a speed of $3000 \mathrm{rpm}$. Then, $10 \%$ black rice bran extract was added gradually after the emulsion began to form. Homogenization process was carried out again for the next 15 minutes at 3000 rpm until a homogeneous lotion was developed, then cooled until it reached room temperature.

\subsubsection{Product Evaluation on Skin}

This clinical trial was approved by the Ethics Committee of University of Indonesia (protocol number 19 - 10 1170, version: 00, September 2019). The samples in this study included 34 healthy women aged 18 - 25 years.

\subsubsection{Inclusion Criteria}

The participants of this study included 34 females aged 18 - 25 years, who were students of the Faculty of Pharmacy, University of Indonesia, with an Asian race. The participants were requested to discontinue applying other cosmetic products to the forearm's skin within a week before and during the study. An informed consent was obtained from all participants.

\subsubsection{Exclusion Criteria}

The exclusion criteria were women with skin disorders such as psoriasis, acne, allergies, wounds, scars, and other skin diseases; pregnant, menopausal, lactating, and smoker women; women suffering from illness, taking oral or topical medications that affect skin conditions; and unwillingness to follow the research.

\subsubsection{Irritation Test}

In this study, the lotion containing $10 \%$ black rice bran extract and placebo were tested using Finn chamber patches attached to the skin on the back. The patches were then removed after 24 hours. Skin reactions were observed and evaluated after 1 hour, 24 hours, and 72 hours from the removal of patches. The reactions observed were in the form of allergies and irritation objectively and subjectively $(14,15)$.

\subsubsection{Lotion Application}

Lotion was applied on volar forearm, which represents the facial skin anatomy because its skin surface is smooth, hairless, and has few sebaceous glands. Therefore, testing the benefits of facial care products such as brightening, moisturizing, and anti-aging products on the volar section is very relevant (16). The application of the lotion containing $10 \%$ black rice bran extract and the lotion containing the placebo as much as $0.5 \mathrm{~g}$ (area $40-50 \mathrm{~mm}^{2}$ ) was carried out two times daily. We labeled the lotions as 'Right' and 'Left' to help participants apply them correctly. Researchers and volunteers did not know the content of each lotion (double-blind). This clinical study was conducted from February to March 2020. 


\subsubsection{Measurement of Skin Brightness and Erythema Level}

Measurement of the skin brightness and erythema level using Mexameter MX-18 (Courage + Khazaka Electronic, Köln, Germany) was carried out at first when the lotion was not applied (day 0), then measured again after day 14 to assess the lotion's benefits. Mexameter is a spectrophotometer measurement technique based on the reflection and absorption of light. The results are displayed in 1 second as a melanin and erythema index number between 0 and 999. The melanin index is an indicator that measures the level of pigmentation in the skin. The erythema index is an indicator that measures the level of erythema on the skin.

Mexameter reads the melanin index at $660 \mathrm{~nm}$ and 880 $\mathrm{nm}$. In comparison, the erythema index (hemoglobin) on the device is read at $568 \mathrm{~nm}$ and $660 \mathrm{~nm}$ to eliminate skin discoloration bias caused by other factors such as bilirubin.

Measurements using this tool were carried out vertically perpendicular to the volar. Mexameter worked when contacted with the skin. Measurements were taken for 3 seconds until a 'beep' sound was heard. Then, the screen showed the measured skin brightness level. The Mexameter was not moved during measurement.

\section{Result and Discussion}

The results were tested with a paired $t$-test by GraphPad Prism 8.3.0 software. The lotion test containing 10\% black rice bran extract and placebo results mean melanin index measurement before applying the lotions (day 0) and then re-measured at the end of the test (day 14) are shown in Table 1 .

From the measurement data obtained, a paired $t$ test was performed to determine statistical significance. The results of the paired $t$-test showed a significant decrease in the melanin index (P-value $<0.0001$ ) in the forearm applied with lotion test (containing 10\% black rice bran extract) and a slight insignificant decrease in the melanin index (P-value $=0.3311)$ in the forearm applied with placebo. The data tested statistically passed the Kolmogorov-Smirnov normality test and the F-Fisher homogeneity test. Mexameter can also show the erythema index. Erythema index measurement was done at first before using the lotion (day 0), then re-measured after day 14 to assess the lotion's benefits. The results are displayed in Table 2.
The results of the paired $t$-test showed a significant decrease in erythema index in both intervention (P-value $<0.0001)$ and placebo $(\mathrm{P}=0.0223)$ groups. The data tested statistically passed the Kolmogorov-Smirnov normality test and the F-Fisher homogeneity test.

In this study, a significant decrease in the melanin index and the skin's erythema index was recorded when the skin was applied with a lotion containing $10 \%$ black rice bran extract. The erythema index of the skin in the placebo group also decreased significantly. In this study, both lotions reduced the erythema index. A decrease in the erythema index indicates that the lotion did not irritate the skin (17). Water content above $60 \%$ in the preparation causes a cold feeling after applying both lotions to the skin (18).

The skin lightening mechanism is a complex process that can be obtained through the tyrosinase inhibition pathway, inhibition of pigment production, inhibition of melanosome transfer activated by PAR-2 (proteaseactivated receptor), and reactive oxygen species reduction (19).

The extract of black rice bran could inhibit the activity of the tyrosinase enzyme. Black rice bran extract contains gamma oryzanol, which belongs to a phenol group (8) with a strong potential as an inhibitor of the tyrosinase enzyme.

Phenolic compounds have a good affinity for the tyrosinase enzyme, thereby preventing the formation of dopachrome. Competitive inhibitors, such as phenol, generally have a substrate-like structure. Glucosides, protonic acid, vanillic acid, and anthocyanins in black rice bran are tyrosinase inhibitors $(20,21)$.

In a study conducted by Jun et al. (3), gamma oryzanol inhibited pigment production in B16 melanoma cells by inhibiting transcription of microphthalmia-associated transcription factor (MITF), which can stimulate melanin formation. In general, antioxidants reduced Melanocytestimulating hormone (MSH) activity to inhibit the expression of MITF (22).

Jung et al. showed a strong correlation between phenol and Oxygen radical absorbance capacity (ORAC) values $(r=0.6770)$ in 21 types of Korean rice bran, including black rice bran (22). The ORAC value obtained reached $1101.31 \mu \mathrm{M}$ per Trolox Equivalent/g. Gamma oryzanol in black rice bran is a strong antioxidant. The potential is stronger than vitamin E, namely alpha-tocopherol, alpha tocotrienol, gamma-tocopherol, and gamma-tocotrienol (23). Anthocyanins, flavonoids responsible for the color pigment in black rice bran, are also powerful antioxidants. 


\begin{tabular}{|c|c|c|c|c|c|}
\hline \multirow{2}{*}{ Treatment } & \multicolumn{5}{|c|}{ Melanin Index } \\
\hline & Day 0 (Mean) & Day 14 (Mean) & Deviation & Standard Deviation & P-Value \\
\hline Lotion test & 240.21 & 214.38 & 25.82 & 21.37 & $<0.0001$ \\
\hline Placebo & 232.77 & 229.74 & 3.03 & 17.96 & 0.3311 \\
\hline \multirow{2}{*}{ Treatment } & \multicolumn{5}{|c|}{ Erythema Index } \\
\hline & Day o (Mean) & Day 14 (Mean) & Deviation & Standard Deviation & P-Value \\
\hline Lotion test & 196.09 & 173.91 & 22.18 & 26.41 & $<0.0001$ \\
\hline Placebo & 196.69 & 186.35 & 10.34 & 25.13 & 0.0223 \\
\hline
\end{tabular}

This component accounts for $20 \%$ of the total flavonoids in black rice bran (24). Antioxidants demonstrate some efficacy in downregulating UV induced hyperpigmentation in the skin (20).

Antioxidants in anthocyanins are inhibitors of inflammatory mediators, namely by inhibiting the production of TNF- $\alpha$, IL-6, and NO in macrophages that are activated by lipopolysaccharides (24).

In this study, there was a significant decrease in both melanin and erythema indices after applying a lotion containing 10\% black rice bran extract. Mexameter read the melanin index at $660 \mathrm{~nm}$ and $880 \mathrm{~nm}$. In comparison, the erythema index (hemoglobin) on the device was read at $568 \mathrm{~nm}$ and $660 \mathrm{~nm}$ to eliminate skin discoloration bias caused by other factors such as bilirubin. Hemoglobin also played a role in skin color (25) because deoxyhemoglobin could be read at a wavelength of $630-700 \mathrm{~nm}$ (26). A correlation test was also conducted in this study to measure the relationship between melanin and erythema index.

The results of Pearson's correlation test (Figure 1) showed that the decrease in the melanin and erythema index in the right arm (lotion test) had a weak correlation with a correlation coefficient of 0.366 .

Melanin formation occurs in the epidermis, while hemoglobin is found in blood vessels located in the dermis layer (25). In clinical studies on UV-induced skin, there was an increase in the melanin index (tanning) and deoxyhemoglobin, causing the skin to become darker. The tanning process takes place from the seventh day after induction and lasts for three weeks. Meanwhile, the increase in deoxyhemoglobin lasts since exposure on the first day and could persist for up to two weeks (26). Melanin index is a better parameter in determining skin color than the erythema index because it is less affected by blood flow (27).
A decrease in the erythema index indicates that the lotion formulation has a soft texture and does not irritate the skin (17).

\section{Conclusions}

According to the results of this study, the lotion containing $10 \%$ black rice bran extract was effective as a skin lightener because it effectively reduced skin melanin production when applied topically. The formulation had no harmful effects on the skin and could be used as natural skin-lightening product. However, the long-term safety study of lotion containing $10 \%$ black rice bran extract is recommended.

\section{Footnotes}

Authors' Contribution: Study concept and design: MJ; Acquisition of data: AV; Analysis and interpretation of data: MJ and AV; Drafting of the manuscript: AV; Critical revision of the manuscript for important intellectual content: MJ and EP; Statistical analysis: MJ and EP; Administrative, technical, and material support: AV; Study supervision: MJ and EP.

\section{Clinical Trial Registration Code: IRCT20210412050942N1}

Conflict of Interests: There are no conflicts of interest to declare.

Ethical Approval: This study was approved by the Ethics Committee of the Faculty of Medicine, University of Indonesia (protocol number 19-10-1170, version: 00, September 2019). 


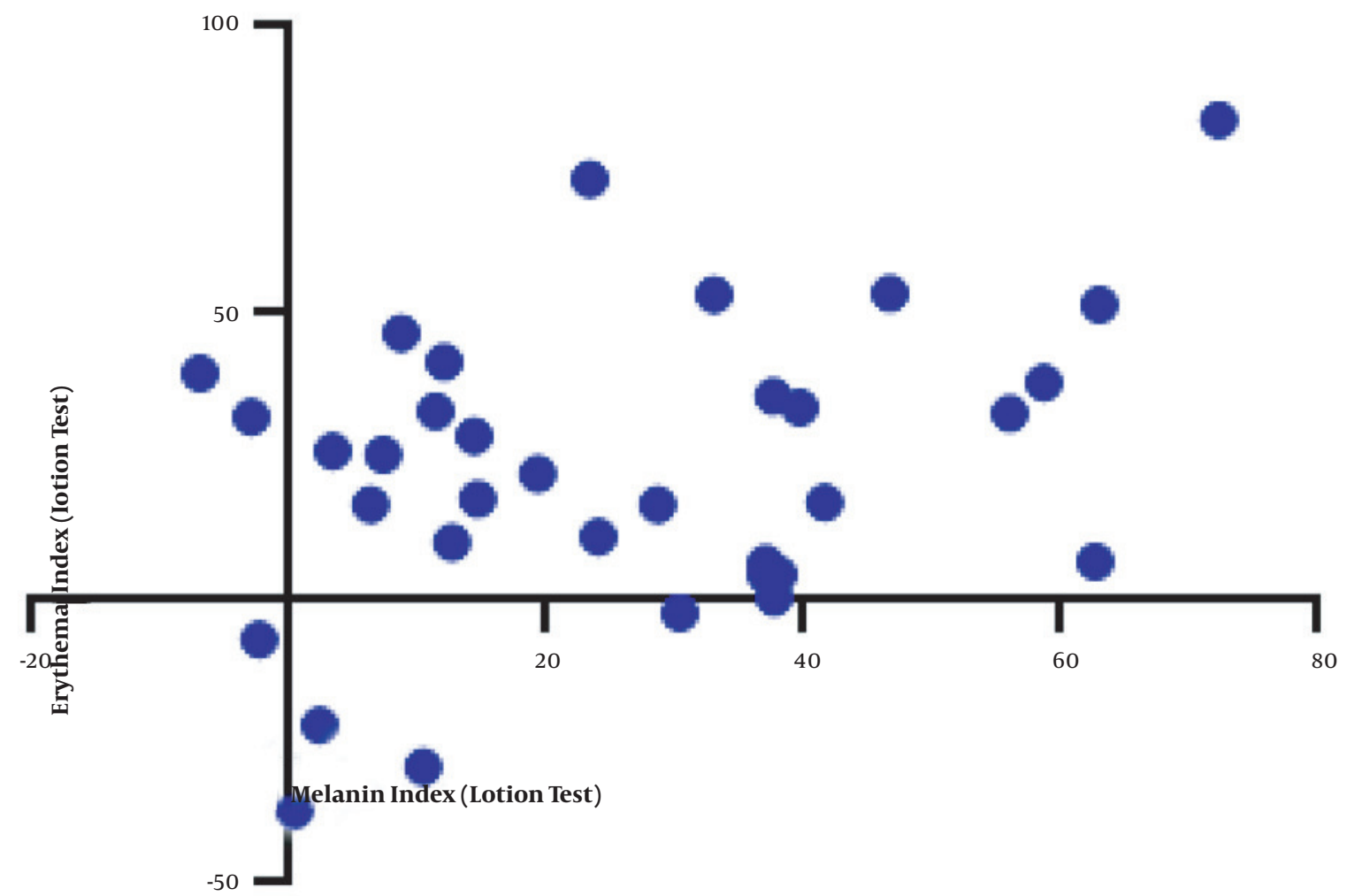

Figure 1. Pearson's Correlation Test Results

Funding/Support: This research was supported by the Directorate of Research and Community Engagements, Integrated Laboratory and Research Center, Universitas Indonesia.

\section{Informed Consent: An informed consent obtained from} all participants.

\section{References}

1. Serre C, Busuttil V, Botto JM. Intrinsic and extrinsic regulation of human skin melanogenesis and pigmentation. Int J Cosmet Sci. 2018;40(4):328-47. doi: 10.1111/ics.12466. [PubMed: 29752874].

2. Videira IF, Moura DF, Magina S. Mechanisms regulating melanogenesis. An Bras Dermatol. 2013;88(1):76-83. doi: 10.1590/s036505962013000100009. [PubMed: 23539007]. [PubMed Central: PMC3699939].

3. Jun HJ, Lee JH, Cho BR, Seo WD, Kang HW, Kim DW, et al. Dual inhibition of gamma-oryzanol on cellular melanogenesis: inhibition of tyrosinase activity and reduction of melanogenic gene expression by a protein kinase A-dependent mechanism. J Nat Prod. 2012;75(10):170611. doi: 10.1021/np300250m. [PubMed: 23031087].
4. Tilaar A, Ranti A, Mun'im A. The efficacy study of snake fruit (Salacca edulis reinw var. bongkok) extract as skin lightening agent. Pharmacogn J. 2017;9(2):235-8. doi: 10.5530/pj.2017.2.39.

5. Kerdudo A, Burger P, Merck F, Dingas A, Rolland Y, Michel T, et al. Development of a natural ingredient - Natural preservative: A case study. Comptes Rendus Chimie. 2016;19(9):1077-89. doi: 10.1016/j.crci.2016.06.004.

6. S. Abdel-Kader M, Alqasoumi SI, S. Al-Dosari M, M. AlSheikh A. Evaluation of the hepatoprotective effect of Fumaria parviflora and Momordica balsamina from Saudi folk medicine against experimentally induced liver injury in rats. Res J Med Plant. 2009;3(1):9-15. doi: 10.3923/rjmp.2009.9.15.

7. Miyazawa M, Oshima T, Koshio K, Itsuzaki Y, Anzai J. Tyrosinase inhibitor from black rice bran. J Agric Food Chem. 2003;51(24):6953-6. doi: 10.1021/jfo30388s. [PubMed: 14611153].

8. Vardhani A, Jufri M, Purwaningsih E. Potency of $\Gamma$-oryzanol-rich black rice bran (Oryza Sativa L. Indica) extract for tyrosinase inhibition. Int JPharm Pharm Sci. 2020:90-3. doi: 10.22159/ijpps.2020v12i5.37197.

9. Ruen-Ngam D, Thawai C, Nokkoul R, Sukonthamut S. Gammaoryzanol extraction from upland rice bran. Int J Biosci Biochem Bioinform. 2014;4(4):252-5. doi: 10.7763/ijbbb.2014.V4.350.

10. Trinovita E, S S, Saputri FC, Mun'im A. Enrichment of the gamma oryzanol level from rice bran by addition of inorganic salts 
on ionic liquid 1-butyl-3- methylimidazolium hexafluorophosphate ([BMIM] PF6) extraction. J Young Pharm. 2017;9(4):555-8. doi: 10.5530/jyp.2017.9.106.

11. Laokuldilok T, Shoemaker CF, Jongkaewwattana S, Tulyathan V. Antioxidants and antioxidant activity of several pigmented rice brans. J Agric Food Chem. 2011;59(1):193-9. doi: 10.1021/jfi03649q. [PubMed: 21141962].

12. Goufo P, Trindade H. Rice antioxidants: Phenolic acids, flavonoids, anthocyanins, proanthocyanidins, tocopherols, tocotrienols, gamma-oryzanol, and phytic acid. Food Sci Nutr. 2014;2(2):75104. doi: 10.1002/fsn3.86. [PubMed: 24804068]. [PubMed Central: PMC3959956].

13. Chang TS. An updated review of tyrosinase inhibitors. Int J Mol Sci. 2009;10(6):2440-75. doi: 10.3390/ijms10062440. [PubMed: 19582213]. [PubMed Central: PMC2705500].

14. Igielska-Kalwat J, Goscianska J, Witkowska B, Nowak I. In vivo studies of substances used in the cosmetic industry. Postepy Dermatol Alergol. 2016;33(3):163-9. doi: 10.5114/ada.2016.60607. [PubMed: 27512349]. [PubMed Central: PMC4969411].

15. Lazzarini R, Duarte I, Ferreira AL. Patch tests. An Bras Dermatol. 2013;88(6):879-88. doi: 10.1590/abd1806-4841.20132323. [PubMed: 24474094]. [PubMed Central: PMC3900336].

16. Bazin R, Fanchon C. Equivalence of face and volar forearm for the testing of moisturizing and firming effect of cosmetics in hydration and biomechanical studies. Int J Cosmet Sci. 2006;28(6):453-60. doi: 10.1111/j.1467-2494.2006.00352.x. [PubMed: 18489290].

17. Kausar R, Akhtar N. Evaluation of depegmenting and antierythemic effects of cosmetic emulgels containing raspberry fruit extract on human cheek skin. Int J Pharm Pharm Sci. 2016;9(1). doi: 10.22159/ijpps.2017v9i1.15123.

18. Draelos ZD. Cosmetic dermatology: Product \& Procedures. New Jersey: Wiley-Blackwell; 2010.

19. Smit N, Vicanova J, Pavel S. The hunt for natural skin whitening agents. Int J Mol Sci. 2009;10(12):5326-49. doi: 10.3390/ijms10125326. [PubMed: 20054473]. [PubMed Central: PMC2801997].

20. Nahhas AF, Abdel-Malek ZA, Kohli I, Braunberger TL, Lim HW, Hamzavi IH. The potential role of antioxidants in mitigating skin hyperpigmentation resulting from ultraviolet and visible lightinduced oxidative stress. Photodermatol Photoimmunol Photomed. 2019;35(6):420-8. doi:10.1111/phpp.12423. [PubMed: 30198587].

21. Pang Y, Ahmed S, Xu Y, Beta T, Zhu Z, Shao Y, et al. Bound phenolic compounds and antioxidant properties of whole grain and bran of white, red and black rice. Food Chem. 2018;240:212-21. doi: 10.1016/j.foodchem.2017.07.095. [PubMed: 28946264].

22. Jung TD, Shin GH, Kim JM, Choi SI, Lee JH, Lee SJ, et al. Comparative analysis of gamma-oryzanol, beta-glucan, total phenolic content and antioxidant activity in fermented rice bran of different varieties. Nutrients. 2017;9(6). doi: 10.3390/nu9060571. [PubMed: 28587204]. [PubMed Central: PMC5490550].

23. Xu Z, Hua N, Godber JS. Antioxidant activity of tocopherols, tocotrienols, and gamma-oryzanol components from rice bran against cholesterol oxidation accelerated by 2,2'-azobis(2methylpropionamidine) dihydrochloride. J Agric Food Chem. 2001;49(4):2077-81. doi: 10.1021/jfo012852. [PubMed:11308370].

24. Limtrakul P, Semmarath W, Mapoung S. Anthocyanins and proanthocyanidins in natural pigmented rice and their bioactivities. Phytochemicals in Human Health. BoD - Books on Demand; 2020.

25. Agache P, Humbert P. Measuring the skin. 2004. doi: 10.1007/978-3-66208585-1.

26. Stamatas GN, Kollias N. Blood stasis contributions to the perception of skin pigmentation. J Biomed Opt. 2004;9(2):315-22. doi: 10.1117/1.1647545. [PubMed: 15065897].

27. Takiwaki H. Measurement of skin color: practical application and theoretical considerations. J Med Invest. 1998;44(3-4):121-6. [PubMed: 9597799]. 